\title{
Actitudes, percepciones y uso de Internet y las redes sociales entre los adolescentes de la comunidad gallega (España)
}

\author{
Antonio Rial*, Patricia Gómez, Teresa Braña y Jesús Varela
}

Universidad de Santiago de Compostela

\begin{abstract}
Resumen: Investigadores e instituciones han venido mostrando en los últimos años una creciente preocupación por el uso de Internet entre los adolescentes. Su impacto a nivel psicológico y conductual se traduce a menudo en la aparición de conductas de riesgo, fracaso escolar y problemas familiares. Habida cuenta del interés que el tema despierta a diferentes niveles, este trabajo se plantea con una doble intención: (1) disponer de datos que permitan conocer desde un punto de vista descriptivo cuáles son las actitudes, percepciones y hábitos de uso de Internet y las redes sociales entre los adolescentes y, (2) profundizar en su comprensión, contribuyendo así al diseño de estrategias que favorezcan un uso más racional y saludable de la Red. Sobre una encuesta a la población de escolares de Enseñanza Secundaria Obligatoria de la comunidad gallega, en la que participaron un total de 2339 individuos, los resultados obtenidos permiten constatar el alto grado de implantación de Internet en la población objeto de estudio y calibrar con datos empíricos la magnitud del problema. A pesar de que las cifras obtenidas no justifican una actitud alarmista, sí advierten de la necesidad de poner en marcha planes de acción concretos de manera inmediata.

Palabras clave: Internet; redes sociales; adolescentes; nuevas tecnologías; ciberdependencia.
\end{abstract}

Title: Attitudes, perceptions and Internet and social networks use among Galician (Spain) teens.

Abstract: Researchers and institutions have shown an increasing concern about how adolescents might misuse the Internet. Its psychological and behavioral impact often translate into the emergence of risk behaviors, school failure and family problems. Given the interest that this issue has generated on an increasingly wider scale, the aim of this paper is twofold: (1) to provide data to determine, from a descriptive point of view, what exactly are the attitudes, perceptions and habits of adolescent Internet and social networks use and (2) a deeper understanding of the issue, contributing to the design of prevention and control strategies which will encourage a more rational and healthy Net use. On the basis of a survey of Compulsory Secondary School students from Galicia, which involved a total of 2339 individuals, the results obtained demonstrate the high level of Internet use penetration among the studied population and make it possible to gauge the magnitude of the problem with empirical data. Although the obtained numbers do not justify an alarmist attitude, they do indicate the need to implement specific action plans immediately.

Key words: Internet; social networks; adolescents; new technologies; ciberdependence.

\section{Introducción}

Hoy en día resulta difícil pensar en una sociedad sin las nuevas tecnologías. La telefonía móvil, Internet y las redes sociales tienen una presencia en nuestras vidas que no podríamos imaginar hace tan solo una década. La realidad pone de manifiesto el papel que dichas herramientas han adquirido en el día a día de niños, adolescentes, jóvenes, adultos y mayores. Los datos facilitados por el Instituto Nacional de Estadística (INE, 2013) ponen de relieve que el teléfono móvil llega al $96.1 \%$ de los hogares españoles, mientras que el $73.4 \%$ de las viviendas con al menos un miembro de entre 16 y 74 años dispone de ordenador. Además, el 71.6\% de la población española de esta franja de edad ha utilizado Internet en los tres últimos meses, porcentaje similar al obtenido para el conjunto de la Unión Europea (75\%) (Seybert y Reinecke, 2013).

A pesar de su relativa "juventud", a día de hoy la implantación de Internet es masiva. La denominada Red de Redes ha pasado de un ámbito militar y científico, acotado para unos pocos, a convertirse en una herramienta cuyo uso se ha generalizado más allá de barreras geográficas, demográficas, socioeconómicas, culturales e ideológicas. En el caso de España el 69.8\% de los hogares tiene acceso a la Red (lo que significa que existen casi 11.1 millones de viviendas familiares conectadas a Internet en nuestro país) (INE, 2013). Es-

* Dirección para correspondencia [Correspondence address]: Antonio Rial Boubeta. Área de Metodología de las Ciencias del Comportamiento. Facultad de Psicología. Universidad de Santiago de Compostela. Campus Vida s/n 15782 Santiago, A Coruña (España). E-mail: antonio.rial.boubeta@usc.es tos datos siguen la tendencia de la Unión Europea, donde la proporción de hogares con acceso a Internet alcanza el 79\% en 2013, lo cual representa un incremento del 30\% comparado con 2006 (Seybert y Reinecke, 2013).

Internet ha sido capaz de mostrar su utilidad en múltiples áreas de la actividad humana, desde la búsqueda de información en ámbitos académicos o escolares, hasta actividades científicas, profesionales, comerciales, transacciones económicas, actividades de ocio o en las propias relaciones interpersonales. Los últimos datos publicados en la $16^{\mathrm{a}}$ encuesta de la Asociación para la Investigación de Medios de Comunicación (AIMC, 2014) a usuarios de Internet revelan que las principales actividades realizadas en la Red tienen que ver con la búsqueda y aprovechamiento de la información: lectura de noticias de actualidad (86.5\%), consulta de mapas y/o callejeros $(71.4 \%)$ o consulta de previsiones meteorológicas y carteleras de cine/ espectáculos $(70.7 \%$ y $48.1 \%$, respectivamente). Un segundo gran uso estaría centrado en las descargas y disfrute online de contenidos: visualización online de vídeos (80.6\%), escuchar música online $(53.8 \%)$, ver emisiones de cadenas de TV en su web (41.8\%) o ver películas/series online (41.4\%). Mención aparte merecen las redes sociales: un $74.2 \%$ de la población internauta se conecta a ellas diariamente, lo que supone un espectacular ascenso del $45.6 \%$ desde 2008 y la confirmación de que las redes sociales no son una moda pasajera. Por último, es preciso destacar el protagonismo creciente del teléfono móvil, siendo más de 4 de cada 5 internautas $(85.5 \%)$ los que se conectan a través de este dispositivo (AIMC, 2014).

Es cierto que Internet proporciona diferentes beneficios para la sociedad en general, al poner a nuestro alcance distin- 
tas fuentes de conocimiento, convirtiéndose así en un potente instrumento para el aprendizaje y la formación intelectual, profesional y personal. Ha supuesto además la aparición de nuevos tipos de comunicación y relación y ha aportado un medio inagotable para el entretenimiento, la diversión y el esparcimiento. Sin embargo, estas y otras ventajas (facilidad de acceso, inmediatez, globalización, comodidad de uso o anonimato) entrañan también un cierto grado de peligrosidad, derivado de un posible uso inadecuado, desmedido y/o sin control. En el caso de los adolescentes el riesgo es posiblemente mayor. Trabajos recientes (Castellana, SánchezCarbonell, Graner y Beranuy, 2007; Echeburúa y De Corral, 2010; Ruiz-Olivares, Lucena, Pino y Herruzo, 2010; Viñas, 2009; Widyanto y Griffiths, 2006) hacen énfasis en el potencial uso inapropiado de la Red y sus consecuencias entre los más jóvenes, así como en el impacto psicológico y conductual que este puede provocar. Las alteraciones comportamentales, la pérdida de control, el sentimiento de culpa, el aislamiento, los conflictos familiares o el descenso en el rendimiento académico son solo algunas de las consecuencias perniciosas destacadas por los investigadores.

Según los últimos datos proporcionados por el INE (2013), el uso del ordenador en menores de entre 10 y 15 años es prácticamente universal $(95.2 \%)$, situándose en el 91.8\% en el caso de Internet. Según el Estudio sobre hábitos seguros en el uso de las TIC por niños y adolescentes y e-confianza de sus padres, realizado por el Instituto Nacional de Tecnologías de la Comunicación (INTECO, 2009) los niños, por lo general, se aproximan de un modo más natural a Internet que los adultos, ya que no solo buscan un servicio, sino que "están en Internet", formando parte de su vida cotidiana. De hecho, un $75 \%$ de los niños/as declaran que Internet les gusta "mucho o bastante más que otras cosas". Recientes trabajos han aportado datos en la misma dirección, constatando la precocidad a este nivel: antes de los 9 años, el 59\% utiliza Internet para visitar páginas web, casi un tercio comparte fotos y vídeos, el $21 \%$ tiene correo electrónico y una décima parte se inicia ya en el uso de las redes sociales. A partir de los 14 años, el uso de redes sociales supera el $80 \%$, hasta alcanzar el $85 \%$ a los 17 años (Bringué y Sádaba, 2009).

Desde una perspectiva global, estudios recientes han analizado la situación que viven los menores en el universo de las TIC (Lenhart, Madden, Smith, Purcell, Zickuhr y Rainie, 2011; Seybert y Reinecke, 2013). Es precisamente en este marco de preocupación transfronteriza donde nace el proyecto europeo EU Kids Online, elaborado al amparo de la Comisión Europea, y cuya tercera parte se encuentra actualmente en fase de desarrollo (Livingstone y Haddon, 2011). La primera parte (EU Kids Online I, 2006-2009) trataba de evaluar el uso que los niños hacen de Internet en los 25 países europeos participantes y elaborar recomendaciones sobre políticas públicas que promuevan un uso seguro de este (Livingstone y Haddon, 2009). La segunda parte (EU Kids Online II, 2009-2011) pretendía mejorar la base de conocimiento relativo a las experiencias y prácticas tanto de los menores, como de sus padres en el uso peligroso de Internet y las nuevas tecnologías online en Europa (Livingstone, Haddon, Görzig y Ólafsson, 2011a). Sus conclusiones sirvieron para evidenciar que con frecuencia los padres no son conscientes de los riesgos que experimentan sus hijos en Internet: solo un $28 \%$ de los padres bloquea o filtra webs y únicamente un $23 \%$ realiza un seguimiento de las webs visitadas por sus hijos (Livingstone, Haddon, Görzig y Ólafsson, 2011b). Paralelamente, en Oceanía se ha desarrollado el proyecto AU Kids Online (2011), con similares propósitos al proyecto europeo (Green, Brady, Ólafsson, Hartley y Lumby, 2011).

Todos estos trabajos no hacen más que mostrar el enorme interés que el tema viene suscitando desde hace más de una década, proliferando numerosas investigaciones y dando lugar a un volumen considerable de literatura científica. Un primer grupo de trabajos ha intentado proporcionar datos epidemiológicos acerca del uso y actitudes hacia Internet de diferentes poblaciones, en especial estudiantes, jóvenes y/o menores (Aslanidou y Menexes, 2008; DeBell y Chapman, 2003; Graner, Beranuy, Sánchez, Chamarro y Castellana, 2007; Ruiz-Olivares et al., 2010). Uno de los problemas de algunos de estos estudios suele residir en sus limitaciones muestrales, ya que habitualmente se centran en segmentos poblacionales específicos, limitando la validez externa de los resultados. Ello se contrapone con el énfasis que diferentes autores hacen en la necesidad de tener en cuenta las diferencias culturales, generacionales y sociodemográficas que subyacen en el uso de Internet (Gross, 2004; Li y Kirkup, 2007; Patchin y Hinduja, 2010; Schumacher y Morahan-Martin, 2001; Weiser, 2000) y que no hacen más que justificar la necesidad de llevar a cabo estudios cada vez más ambiciosos, capaces de proporcionar resultados generalizables.

Un segundo bloque de trabajos tiene que ver con la pregunta de dónde acaba el uso normal de Internet y dónde comienza el no saludable. La confusión terminológica existente no hace más que reflejar la falta de acuerdo que sigue existiendo al respecto. Baste decir que en la actualidad ni el DSM-5 ni la CIE-10 incluyen una categoría diagnóstica específica referida a la posible adicción a Internet o ciberdependencia. Cuando se hace referencia al uso peligroso de Internet la heterogeneidad terminológica es manifiesta: adicción a Internet (Chou y Hsiao, 2000; Goldberg, 1995; Kandell, 1998; Young, 1998a), uso poco sano o enfermizo (Scherer, 1997), uso compulsivo (Greenfield, 1999; Meerkerk, Van den Eijnden y Garretsen, 2006), uso patológico (Davis, 2001; Morahan-Martin y Schumacher, 2000), uso problemático (Caplan, 2002; Shapira et al., 2003), uso excesivo (Hansen, 2002), uso no regulado (LaRose, Lin y Eastin, 2003) o dependencia de Internet (Chen, Tarn y Han, 2004). El uso de una expresión concreta suele reflejar una concepción particular del problema. Términos como adicción a Internet o uso patológico de Internet sugieren que este fenómeno debiera ser incluido como un trastorno psiquiátrico independiente (Demetrovics, Szeredi y Rózsa, 2008) en los distintos manuales diagnósticos, aunque tampoco existe un claro consenso acerca de qué grupo de trastornos debe- 
rían ser el punto de partida para su descripción: trastornos por uso de sustancias o trastornos del control de impulsos (Shapira et al., 2003). Por su parte, el empleo de términos como uso problemático o excesivo pone el acento en la identificación de síntomas impulsivos y compulsivos, así como de problemas educativos derivados de un uso excesivo de Internet (Demetrovics et al., 2008). Numerosos trabajos han realizado aproximaciones teóricas y cualitativas al respecto, intentando dilucidar el marco más idóneo en el que encuadrar este concepto (Douglas et al., 2008; Yellowlees y Marks, 2007). Sin embargo, a día de hoy esta es una cuestión todavía por resolver.

Un tercer bloque de trabajos aborda la difícil tarea de desarrollar herramientas de medida y diagnóstico en un campo en el que la conceptualización del fenómeno está llena de controversias, por lo que han sido propuestos diferentes instrumentos. Goldberg (1995) parodió el fenómeno de la adicción a Internet utilizando unos criterios homólogos a los de la dependencia por substancias psicoactivas. Por su parte, Brenner (1997), tomando como referencia los criterios para la dependencia de substancias, creó el Internet-Related Addictive Behavior Inventory. Young (1998a), a su vez, desarrolló el Diagnostic Questionnaire, así como el Internet Addiction Test (Young, 1998b). Años más tarde, aparece la Pathological Internet Use scale (Morahan-Martin y Schumacher, 2000) y Davis, Flett y Besser (2002) publican la Online Cognitive Scale basándose en el modelo cognitivo-conductual (Davis, 2001) derivado de la psicopatología. Poco después se elabora el Thatcher's Problematic Internet Use Questionnaire (Thatcher y Goolam, 2005) y el Demetrovics' Problematic Internet Use Questionnaire (Demetrovics et al., 2008), así como otras escalas adaptadas a distintas poblaciones y culturas (Chow, Leung, Ng y Yu, 2009). En España, Echeburúa (2003) construyó el Test de Adicción a Internet y Gracia, Vigo, Fernández y Marcó (2002) diseñaron la escala PRI (problemas relacionados con el uso de Internet), basándose en los criterios de juego patológico y dependencia de sustancias. Posteriormente, Jenaro, Flores, Gómez-Vela, González-Gil y Caballo (2007) elaboraron la Internet Over-use Scale siguiendo los criterios de juego patológico, y Beranuy, Chamarro, Graner y Carbonell (2009) desarrollaron el Cuestionario de Experiencias Relacionadas con Internet (CERI).

A estos tres grandes bloques cabría añadir estudios que comparan a los individuos que usan Internet de un modo excesivo con aquellos que realizan un uso normal (Scherer, 1997; Yang y Tung, 2007; Young, 1998a); estudios de casos (Griffiths, 2000; Young, 1996); estudios correlacionales que estiman la relación existente entre el uso excesivo de Internet con otras variables -bienestar, rendimiento académico, control parental, determinada sintomatología psiquiátrica, características de personalidad, etc.- (Subrahmanyam y Lin, 2007; Yang, Choe, Baity, Lee y Cho, 2005); estudios que profundizan en las consecuencias o efectos de esta posible adicción (Weiser, 2001); estudios que formulan estrategias de seguridad y prevención (García-Piña, 2008; Echeburúa y De Corral, 2010); estudios que proponen o recopilan modelos explicativos de la adicción a Internet (Davis, 2001; Luengo, 2004; Young, 1999), así como recientes revisiones de los estudios realizados (Carbonell, Fúster, Chamarro y Orbest, 2012).

En definitiva, el desarrollo de la investigación en este campo y la abundante literatura existente no hacen más que constatar el enorme interés que ha suscitado y las controversias generadas. La creciente preocupación por los riesgos y consecuencias negativas que el uso inadecuado de Internet puede conllevar para los adolescentes justifican la necesidad de realizar nuevos estudios, que permitan disponer de una base de conocimiento cada vez más rigurosa, con la que calibrar mejor la magnitud del problema.

El presente estudio se plantea con el objetivo fundamental de conocer los hábitos de uso de Internet y las redes sociales entre los adolescentes, profundizando en sus actitudes, percepciones y creencias. La finalidad última es doble: a nivel descriptivo, la información recogida debe traducirse en un mejor conocimiento de la realidad y, a nivel aplicado, los resultados deben traducirse en recomendaciones concretas a diferentes niveles, que habrán de reflejarse en el diseño de estrategias de prevención y control avalados empíricamente.

\section{Método}

\section{Participantes}

Para dar cuenta de los objetivos señalados se recurrió a una metodología selectiva. Concretamente, se llevó a cabo una encuesta entre la población de estudiantes de Enseñanza Secundaria Obligatoria (ESO) de la comunidad autónoma de Galicia. Según datos de la propia Consellería de Educación de la Xunta de Galicia dicha población asciende a aproximadamente 89000 individuos. Para la selección de la muestra se utilizó un muestreo bietápico: por conglomerados, para la selección de las unidades de primer nivel (un total de 29 centros seleccionados de forma aleatoria, tanto públicos como privados/concertados, tanto de carácter urbano como rural y de las cuatro provincias gallegas, respetando las cuotas existentes a nivel poblacional). Para la selección de las unidades de segundo nivel (individuos) se utilizó un muestreo por cuotas, según el Género y el Ciclo. La muestra final estuvo compuesta por un total de 2339 estudiantes, 1171 mujeres y 1168 hombres, con edades comprendidas entre los 11 y los 18 años $(M=13.77 ; D T=1.34)$. De estos, 1619 asistían a colegios públicos y 720 a colegios privados/concertados; 1239 cursaban el primer ciclo de la ESO $\left(1^{\circ}\right.$ y $\left.2^{\circ}\right)$ y 1100 , el segundo ciclo $\left(3^{\circ}\right.$ y $\left.4^{\circ}\right)$.

\section{Instrumentos}

La recogida de datos se llevó a cabo mediante un cuestionario elaborado expresamente para el presente estudio, dividido en tres bloques: (1) un bloque sobre hábitos de uso de Internet, así como motivos y barreras, información, disponibilidad de aplicaciones y dispositivos, conocimiento y 
utilización de redes sociales y el papel de los padres en este contexto; (2) una escala de actitudes hacia Internet y las redes sociales, compuesta de 12 ítems; y (3) un último bloque en el que se recogían datos sociodemográficos como Género, Edad, Curso, Centro y Provincia.

La escala de actitudes hacia Internet y las redes sociales fue elaborada a partir de las aportaciones de diferentes trabajos (Armstrong, Phillips y Saling, 2000; Castellana et al., 2007; Gracia et al., 2002; Viñas, 2009), de los que fueron seleccionados un total de 12 ítems, que abarcaban diferentes aspectos referidos al modo en cómo ven los sujetos la relación de los adolescentes con Internet y las redes sociales, la relación de uno mismo con estas, así como posibles indicios de un mal uso o abuso de Internet. Lo que a los sujetos se les pedía era que manifestasen su grado de acuerdo con cada ítem, utilizando para ello una escala de respuesta tipo Likert de 5 puntos, desde 1 "Nada de acuerdo" a 5 "Totalmente de acuerdo".

\section{Procedimiento}

Los datos fueron recogidos en las propias aulas de los centros, en grupos de 15-20 individuos, mediante un cuestionario que cada participante debía cumplimentar de forma individual. La recogida de la información fue supervisada por investigadores de la Universidad de Santiago de Compostela, con experiencia en la realización de este tipo de tareas. Cada sujeto fue informado de la finalidad del estudio y de que los datos iban a ser tratados de manera totalmente confidencial y anónima, ya que en ningún momento se les pedía ni su nombre ni ningún tipo de dato identificativo. Se contó con la colaboración y el consentimiento tanto de la dirección de los centros, como de las respectivas asociaciones de madres y padres de alumnos. La participación fue voluntaria y el tiempo para la cumplimentación del cuestionario osciló entre 20 y 25 minutos.

El número inicial de cuestionarios recogidos fue de 2468 , si bien 129 fueron rechazados tras un exhaustivo proceso de revisión, bien por presentar un excesivo número de valores ausentes, incoherencias o bien por distorsionar las cuotas establecidas.

\section{Resultados}

\section{Resultados a nivel descriptivo}

\section{Hábitos de uso de Internet}

En primer lugar, tal y como se recoge en la Tabla 1, el $60.4 \%$ de los adolescentes reconoce conectarse a Internet todos los días. Un primer dato de interés sería, por tanto, que 6 de cada 10 adolescentes hacen un uso diario o regular de Internet. A estos habría que añadir un $26.8 \%$ que se conecta una o dos veces por semana. Aquellos que usan Internet se conectan, por lo general, entre 1 y 2 horas al día (45.8\%) y lo hacen masivamente desde su casa (88.1\%), aunque un $22.7 \%$ se conecta también desde la casa de sus amigos o familiares y un $15.8 \%$ a través del móvil. Es importante advertir asimismo que un $10.5 \%$ se estaría conectando más de 3 horas al día.

Por lo que se refiere a la franja horaria de conexión lo habitual es hacerlo entre las $16 \mathrm{~h}$ y las $21 \mathrm{~h}(56.8 \%)$. No obstante, casi un $40 \%$ se conecta también entre las $21 \mathrm{~h}$ y las $24 \mathrm{~h}$ y un $5.8 \%$ lo hace incluso a partir de medianoche.

Tabla 1. Hábitos de uso de Internet.

\section{HÁBITOS DE USO}

Frecuencia de - Diaria (todos o casi todos los días): 60.4\%

conexión - Semanal (una o dos veces por semana): $26.8 \%$

- Ocasional (un par de veces al mes): 7.8\%

- Nunca/casi nunca: 5\%

\begin{tabular}{|c|c|}
\hline \multirow{4}{*}{$\begin{array}{l}\text { Tiempo de } \\
\text { conexión }^{1}\end{array}$} & - Menos de 1 h/día: 26.1\% \\
\hline & - Entre 1-2 h/día: 45.8\% \\
\hline & - Entre2-3 h/día: 17.6\% \\
\hline & - Más de 3 h/día: 10.5\% \\
\hline \multirow{5}{*}{$\begin{array}{l}\text { Horarios de } \\
\text { conexión }{ }^{1}\end{array}$} & - De las 8 h a las 14 h: $5.3 \%$ \\
\hline & - De las $14 \mathrm{~h}$ a las $16 \mathrm{~h}: 32.2 \%$ \\
\hline & - De las 16 h a las 21 h: $56.8 \%$ \\
\hline & - De las 21 h a las 24 h: $39.2 \%$ \\
\hline & - A partir de las 24 h: 5.8\% \\
\hline \multirow{7}{*}{$\begin{array}{l}\text { Lugares de } \\
\text { conexión }^{1}\end{array}$} & - Desde mi casa: $88.1 \%$ \\
\hline & - Desde la casa de algún amigo o familiar: $22.7 \%$ \\
\hline & - Desde una cafetería o cíber: $11.5 \%$ \\
\hline & - Desde el móvil: 15.8\% \\
\hline & - Desde el colegio: $12 \%$ \\
\hline & - Desde cualquier lugar con wifi: $6.6 \%$ \\
\hline & - Otros: $3.2 \%$ \\
\hline
\end{tabular}

${ }^{1}$ Porcentaje relativo a los que se conectan al menos de manera ocasional

\section{Motivos de uso}

En cuanto a los motivos de conexión, tal y como se detalla en la Tabla 2, las respuestas de los sujetos son muy variadas, si bien destacan fundamentalmente cuatro: hacer uso de las redes sociales $(85 \%)$, descargar música, películas, vídeos o imágenes (64.4\%), buscar información relacionada con los estudios $(60.2 \%)$ y hacer uso del correo electrónico $(52.1 \%)$. Cabe advertir también que, en términos absolutos, un $28.2 \%$ de los participantes en el estudio afirman ser usuarios de juegos online, de diferentes tipos y/o formatos, tanto de carácter individual como grupal, más allá de los juegos de azar tradicionales. Un último dato digno de mención es que el $36.2 \%$ de los adolescentes manifiesta no conectarse todo lo que le gustaría. Información sobre Internet

Otra de las cuestiones a priori interesantes del presente estudio era pulsar el nivel de información que los propios adolescentes dicen tener acerca de Internet, así como identificar las principales fuentes y demandas de información. En líneas generales, el nivel de información autopercibido es relativamente alto, alcanzando un promedio de 3.52 en una escala de 1 a 5 . Tal y como se recoge en la Tabla 3, el 48.9\% de los adolescentes dicen que su nivel de información es $\mathrm{Al}$ to o Muy alto, mientras que únicamente el $6.9 \%$ se considera poco informado. Por lo que se refiere a las fuentes de información, el $64.8 \%$ se considera autodidacta, el $40.6 \%$ ha 
aprendido a través de familiares y un $38.7 \%$ a través de amigos. Los centros educativos no parecen ser una fuente de información relevante a este nivel (18.6\%). Por último, las demandas de información se centran, sobre todo, en las redes sociales $(45 \%)$, así como en lo relativo a la seguridad y confidencialidad de la Red (41.9\%).

Tabla 2. Principales motivos de uso de Internet. MOTIVOS DE USO

Motivos de - Visitar mi perfil de Tuenti, Facebook y otras redes conexión ${ }^{1} \quad$ sociales: $85 \%$

- Descargar archivos, música, películas, etc.: 64.4\%

- Buscar información relacionada con los estudios: $60.2 \%$

- Consultar el correo electrónico: $52.1 \%$

- Ver series, películas, partidos, etc. : 45.5\%

- Buscar información de todo tipo: $41.8 \%$

- Participar en juegos online: 29.7\%

- Leer el periódico: 12.7\%

- Comprar entradas, música, libros, ropa, etc.: $8.9 \%$

- Entrar en webs de apuestas: 1.5\%

- Otras: 5.8\%

Barreras de - No tengo desde donde conectarme: $37.9 \%$

uso $^{2} \quad-$ No me interesa, no me hace falta, no me parece útil: $27.6 \%$

- No me dejan mis padres: $22.4 \%$

- Por desconocimiento, no sé bien como funciona, para qué sirve, etc. : $6 \%$

- Por desconfianza, por miedo, etc. : $6 \%$

- Otras: $18.1 \%$

Expectativa - Me conecto todo lo que me gustaría: $62.8 \%$

- No me conecto todo lo que me gustaría: 36.2\% - Ns/nc: $1 \%$

${ }^{1}$ Porcentaje relativo a los que se conectan al menos de manera ocasional

2 Porcentaje relativo a los que nunca o casi nunca se conectan

Tabla 3. Información sobre Internet.

INFORMACIÓN

Nivel de informa-- Muy bajo: 1.2\%

ción percibido ${ }^{1}$ - Bajo: $5.8 \%$

- Medio: $44.1 \%$

- Alto: 37.7\%

- Muy alto: $11.2 \%$

Fuentes de - Aprendí yo solo: 64.8\%

información ${ }^{1}$ - Familiares: $40.6 \%$

- Amigos: $38.7 \%$

- Centro escolar: 18.6\%

- Academia: 10.8\%

- Otras: 1.3\%

Demandas de - Redes sociales: $45 \%$

información ${ }^{1}$ - Seguridad y confidencialidad en Internet: $41.9 \%$

- Aspectos técnicos: 34.6\%

- Cómo buscar información: $32 \%$

- Otras: $2.5 \%$

1 Porcentaje relativo a los que se conectan al menos de manera ocasional

\section{Disponibilidad de aplicaciones y dispositivos}

Un dato interesante es que en términos absolutos el 55\% de los adolescentes cuenta con conexión a Internet en su propio cuarto. Además, tal y como se recoge en la Tabla 4, prácticamente 9 de cada 10 adolescentes $(89 \%)$ hacen uso de Messenger, aunque solo el 43.8\% de estos lo utiliza de forma regular. En cuanto a la cámara Web, un $63.2 \%$ dispone de dicho dispositivo, aunque solo el 19.5\% la usa de modo habitual. Profundizando en los usos de Internet, se ha de señalar que 9 de cada 10 adolescentes gallegos/as disponen de correo electrónico $(89.8 \%)$, la mayoría dispone de una única cuenta $(57.6 \%)$, aunque uno de cada cuatro $(25.2 \%)$, de dos y un $17.2 \%$, de tres o más. Por lo que se refiere a la frecuencia de uso del correo, las respuestas encontradas son muy variadas, aunque lo habitual es que lo hagan dos o tres veces a la semana $(27.8 \%)$.

Tabla 4. Disponibilidad de Aplicaciones y Dispositivos APLICACIONES Y DISPOSITIVOS

Conexión en $\quad-55 \%$ de los adolescentes

su cuarto

Cámara Web 1 - No dispongo de cámara web: $36.8 \%$

- Dispongo de cámara web: $63.2 \%$

- La utilizo habitualmente: $19.5 \%$

- No la utilizo habitualmente: $80.5 \%$

Messenger $^{1}$ - No dispongo de Messenger: $11 \%$

- Dispongo de Messenger: 89\%

- Lo utilizo habitualmente: $43.8 \%$

- No lo utilizo habitualmente: $56.2 \%$

Cuentas de correo - No dispongo de correo electrónico: 10.2\%

electrónico $^{1}$ - Dispongo de correo electrónico: $89.8 \%$

- Una sola cuenta: $57.6 \%$

- Dos cuentas: $25.2 \%$

- Entre 3-5 cuentas: 14.5\%

- Más de 5 cuentas: $2.7 \%$

- Todos los días: $18.4 \%$

Frecuencia de

- Entre 2 - 3 veces por semana: 27.8\%

$\begin{array}{ll}\text { consulta del } & \text { - Entre } 2 \text { - } 3 \text { veces por semana } \\ \text { correo electrónico }^{2} & \text { - Una vez a la semana: } 19 \%\end{array}$

- Cada 15 días aproximadamente: $12.3 \%$

- Mensualmente, muy de vez en cuando: $22.5 \%$

${ }^{1}$ Porcentaje relativo a los que se conectan al menos de manera ocasional 2 Porcentaje relativo a los que disponen de correo electrónico

\section{Conocimiento y utilización de redes sociales}

Tal y como se puede observar en la Tabla 5, el nivel de conocimiento de las redes sociales entre los/as estudiantes de ESO es muy elevado. Tuenti y Facebook son las redes sociales más conocidas, con un $96.7 \%$ y un $91.9 \%$ de notoriedad, respectivamente, aunque Twitter (69.7\%) y MySpace $(55.6 \%)$ alcanzan también porcentajes relativamente altos. Un dato especialmente interesante es que el $85.1 \%$ de los/as adolescentes está registrado en al menos una red social, casi el $40 \%$ en dos y hasta un $15.9 \%$ en tres o más. De manera desglosada, cabe informar de que el $81.4 \%$ está registrado en 
Tuenti y un $57 \%$ en Facebook. Por lo que se refiere a las motivaciones que les llevan a hacer uso de las redes sociales, las respuestas son muy variadas, aunque destacan dos por encima de las demás: hablar con amigos y familiares $(67.5 \%)$ y ver fotos, chatear y hacer comentarios $(33.6 \%)$.

Tabla 5. Conocimiento y utilización de redes sociales.

\begin{tabular}{|c|c|c|c|c|c|c|c|c|}
\hline REDES SO & 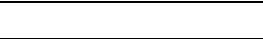 & & & & & & & \\
\hline Número de & s que está registrado ${ }^{1}$ & - Ninguna: & & & & & & \\
\hline & & - Una: $29.7^{\circ}$ & & & & & & \\
\hline & & - Dos: $39.6^{\circ}$ & & & & & & \\
\hline & & - Tres o má & $5.8 \%$ & & & & & \\
\hline Razones $^{1}$ & & - Hablar cor & migos y & miliares: $67.5 \%$ & & & & \\
\hline & & - Ver fotos, & atear y & nentar: $33.6 \%$ & & & & \\
\hline & & - No perder & contact & on aquellos a lo & ue no & o a men & o: $17.1 \%$ & \\
\hline & & - Diversión, & io: 13.3 & 1 & & & & \\
\hline & & - Hablar gra & con am & $\mathrm{s}: 11.6 \%$ & & & & \\
\hline & & - Hacer nue & amigo & $0 \%$ & & & & \\
\hline & & - Colgar fot & vídeos, & .: $9.5 \%$ & & & & \\
\hline & & - Cotillear: 9 & & & & & & \\
\hline & & - Participar & juegos: & & & & & \\
\hline & & - Quedar co & rente: 4 & & & & & \\
\hline & & - Resolver t & as de $\mathrm{cl}$ & (apuntes, exám & s, etc.) & $.3 \%$ & & \\
\hline & & - Otras: 12. & & & & & & \\
\hline & Conoc. $^{1}$ & Perfil $^{1}(\%)$ & Frecue & ia de utilización & & & & \\
\hline & $(\%)$ & & Diaria & $2-3 \mathrm{v} /$ semana & Sem. & Quinc. & Mens. & $\mathrm{Ns} / \mathrm{nc}$ \\
\hline Tuenti & 96.7 & 81.4 & 58.4 & 26.6 & 6.8 & 2.9 & 3.2 & 2.1 \\
\hline Facebook & 91.9 & 57 & 20 & 26.2 & 20.2 & 10.2 & 20.5 & 2.9 \\
\hline Twitter & 69.7 & 14.3 & 16.5 & 16.2 & 16.2 & 11.4 & 36.8 & 2.9 \\
\hline MySpace & 55.6 & 8.1 & 12.6 & 15.3 & 17.9 & 7.9 & 43.2 & 3.1 \\
\hline
\end{tabular}

${ }^{1}$ Porcentaje relativo a los que se conectan al menos de manera ocasional

2 Porcentaje relativo a aquellos que están registrados en cada red social

\section{Papel de los padres}

Otra de las cuestiones de interés en el presente trabajo era explorar el papel de los padres con relación al uso que los adolescentes hacen de Internet. Un primer dato revela que tan solo en el 46\% de los casos existe un control parental al respecto (ver Tabla 6). Estaríamos hablando de un $52.8 \%$ de escolares a los que sus padres no controlan, ni ponen límite alguno a la hora de usar Internet. Un dato complementario es que el $77.9 \%$ de los chicos/as que utilizan

Tabla 6. Papel de los padres con relación a Internet PAPEL DE LOS PADRES

\begin{tabular}{|c|c|}
\hline Control parental (¿te controlan?) ${ }^{1}$ & $\begin{array}{ll}\text { - } & \text { Sí: } 46 \% \\
\text { - } & \text { No: } 52.8 \% \\
\text { - } & \text { Ns } / \text { nc: } 1.2 \%\end{array}$ \\
\hline Discusiones $^{1}$ & $\begin{array}{ll}\text { - } & \text { Sí, muchas veces: } 6.3 \% \\
\text { - } & \text { Sí, de vez en cuando: } 14.6 \% \\
\text { - } & \text { Casi nunca: } 32.9 \% \\
\text { - } & \text { Nunca: } 45 \% \\
\text { - } & \text { Ns } / \text { nc: } 1.2 \%\end{array}$ \\
\hline Utilizan Internet $^{1}$ & $\begin{array}{ll}\text { - } & \text { Sí, habitualmente: } 33.4 \% \\
\text { - } & \text { Sí, de vez en cuando: } 37.5 \% \\
\text { - } & \text { Nunca o casi nunca: } 25.5 \% \\
\text { - } & \text { Ns } / \text { nc: } 3.6 \%\end{array}$ \\
\hline
\end{tabular}

${ }^{1}$ Porcentaje relativo a los que se conectan al menos de manera ocasional
Internet, no han tenido nunca o casi nunca una discusión con sus padres por su uso; mientras que el $6.3 \%$ manifiesta tener problemas muchas veces y el $14.6 \%$, de vez en cuando. Por último, habría que añadir que 1 de cada 4 padres (25.5\%) no han utilizado nunca o prácticamente nunca Internet, dato que contrasta claramente con el porcentaje registrado entre los propios adolescentes (5\%). Estamos, por tanto, ante una brecha generacional considerable, que bien podría estar detrás del escaso control parental encontrado. En concreto, cuando se realiza un contraste de independencia entre las variables utilización de Internet por parte de los padres y control ejercido por estos, se obtiene un resultado significativo $\left(\chi^{2}=21.66 ; p\right.$ $<.001)$, comprobándose que el control es menor entre aquellos padres que no utilizan Internet $(39 \%)$ que entre los que sí lo utilizan $(50.2 \%)$.

\section{Actitudes}

Para estudiar las actitudes hacia Internet y las redes sociales se construyó una escala ad hoc que constaba de 12 ítems extraídos de la literatura sobre el tema. En primer lugar se llevó a cabo un Análisis Factorial Exploratorio, utilizando el Método de Componentes Principales. El índice $K M O$ fue de $.854 \mathrm{y}$ el Test de Esfericidad de Bartlett de $5412.65(p<.001)$. El análisis proporcionó 3 factores, que explicaban conjuntamente el $54.89 \%$ de la Varianza de los datos. En el primero de ellos (con un $32.45 \%$ de varianza 
explicada) saturaban fundamentalmente 5 elementos, todos ellos referidos a posibles consecuencias negativas derivadas de un uso inadecuado de Internet o incluso de un posible riesgo de dependencia. En el segundo factor (que explicaba el 12.28\% de la varianza), saturaban un total de 4 ítems referidos al nivel de apego, vínculo o simpatía que generan las redes sociales e Internet para uno mismo y, por último, el tercer factor (al que correspondería únicamente un $10.16 \%$ de la varianza) estaría representado por 3 ítems referidos a una posible percepción negativa de la relación entre Internet y las redes sociales y los Otros.

Este primer análisis sirvió de base para la realización de un Análisis Factorial Confirmatorio ( $A F C$ ), partiendo de un modelo teórico de tres dimensiones o factores, tal y como se recoge en la Figura 1. En la Tabla 7 se muestran los estadísticos descriptivos para cada uno de los ítems y dimensiones de la escala.

El promedio mayor corresponde a la Dimensión I (Exoactiud Negativa) con un valor de 4.04 sobre 5, siendo el ítem 1 (Creo que cada vez hay más gente de mi edad "enganchada" a Internet $y$ las redes sociales) el que presenta una media mayor (4.36). Por su parte, la dimensión con un promedio menor es la Dimensión III, referida al posible Riesgo de Dependencia (2.54), siendo el ítem 12 el que tiene una media inferior (2.01). Los elementos que presentan una mayor homogeneidad corresponden a la primera dimensión, tanto tomados en conjunto $(D T=0.83)$, como de forma individual. En cuanto a los valores de la asimetría estandarizada, los ítems $1,2,3,5,7$ y 11 presentan una marcada asimetría negativa, con valores absolutos superiores a 3 . Por el contrario, los ítems 8, 10 y 11 presentan una notable asimetría positiva. Con relación a la curtosis, tan solo el ítem 1 presenta un valor por encima de 10, situándose el resto dentro de los límites razonables (Kline, 2005). Por último, el coeficiente de Mardia fue de 8.08 , lo que indica que la hipótesis de normalidad multivariante debería ser rechazada. Sin embargo, trabajos como Rodríguez y Ruíz (2008), señalan como asumibles valores que estén por debajo de 50 .

Tabla 7. Estadísticos descriptivos para los elementos de la escala de actitudes.

\begin{tabular}{|c|c|c|c|c|}
\hline & $M$ & DT & Asimetría & Curtosis \\
\hline \multicolumn{5}{|l|}{ EXOACTITUD NEGATIVA } \\
\hline 1. Creo que cada vez hay más gente de mi edad "enganchada" a Internet y las redes sociales & 4.36 & 0.95 & -19.87 & 11.93 \\
\hline $\begin{array}{l}\text { 2. Algunos/as de mis amigos/as hacen un uso excesivo o poco adecuado de Internet y las redes socia- } \\
\text { les }\end{array}$ & 3.67 & 1.36 & -7.05 & -6.35 \\
\hline 3. Mucha gente utiliza las redes sociales para ligar, tontear, etc. & 4.09 & 1.16 & -14.93 & 2.77 \\
\hline PROMEDIO & 4.04 & 0.83 & & \\
\hline \multicolumn{5}{|l|}{ ENDOACTITUD POSITIVA } \\
\hline 4. Para mí es importante poder conectarme diariamente a Facebook, Tuenti... & 3.19 & 1.41 & -2.65 & -7.37 \\
\hline 5. Internet y las redes sociales son una buena manera de conocer gente y hacer amigos/as & 3.46 & 1.36 & -5.75 & -6.39 \\
\hline 6. Me gusta agregar cada vez más amigos/as a mi perfil de Facebook, Tuenti... & 3.02 & 1.43 & -0.49 & -8.50 \\
\hline 7. Me gusta hacer comentarios en Facebook, Tuenti... y que me respondan & 3.64 & 1.42 & -9.54 & -4.98 \\
\hline PROMEDIO & 3.33 & 1.06 & & \\
\hline \multicolumn{5}{|l|}{ POSIBLE RIESGO DEPENDENCIA } \\
\hline 8. En algunas ocasiones he perdido horas de sueño por usar Internet & 2.06 & 1.43 & 12.21 & -3.75 \\
\hline 9. A veces me conecto más de lo que debería & 2.94 & 1.48 & -0.01 & -8.93 \\
\hline 10. En ocasiones me pongo de mal humor por no poder conectarme & 2.37 & 1.43 & 6.80 & -7.28 \\
\hline 11. Cuando estoy conectado siento que el tiempo vuela y cuando me doy cuenta llevo horas en Internet & 3.34 & 1.45 & -3.61 & -7.90 \\
\hline 12. He descuidado las tareas de estudio por conectarme a Internet & 2.01 & 1.29 & 12.82 & -1.67 \\
\hline PROMEDIO & 2.54 & 1.03 & & \\
\hline
\end{tabular}

A pesar de la ausencia relativa de normalidad, para la estimación de parámetros se utilizó el método de Máxima Verosimilitud $(M L)$, habida cuenta de que trabajos como el de Curran, West y Finch (1996) o Tomás y Oliver (1998), advierten que dicho método es razonablemente robusto ante el incumplimiento de normalidad, cuando se trabaja con muestras grandes como es nuestro caso. No obstante, se utilizaron de manera complementaria otros procedimientos (GLS, $U L S$ y $A D F)$, obteniendo resultados muy similares e incluso con niveles de ajuste más elevados. Además, para intentar garantizar la estabilidad de los resultados se realizó una validación cruzada, comparando el ajuste del modelo para dos submuestras diferentes, obtenidas a partir de la división aleatoria de la base de datos original en dos mitades. Los análisis fueron realizados mediante el programa Amos 20, implementado en el paquete estadístico IBM SPSS Statistics 20.
Los parámetros estimados estandarizados se recogen en la Figura 1 y los índices de bondad de ajuste del modelo $A F C$ en la Tabla 8. Todos las saturaciones factoriales $(\lambda)$ fueron estadísticamente significativas y superiores a .50. Por su parte, las correlaciones entre factores presentan valores relativamente bajos $(\varphi<.50)$, lo que supondría una evidencia de validez discriminante. La excepción es la elevada correlación encontrada entre la Endoactitud Positiva y el Riesgo de Dependencia, que es de .74 , lo cual revela cierto grado de convergencia de ambas dimensiones.

Un análisis detallado de los índices de modificación proporcionados por el programa sugirieron además la liberación de dos parámetros concretos, referidos a la relación entre los errores de medida asociados al ítem 5 y el ítem $6\left(\delta_{5}-\delta_{6}\right)$, por un lado, y al ítem 8 y el $12\left(\delta_{8}-\delta_{12}\right)$, por otro, resultando en 
ambos casos estadísticamente significativos y coherentes desde un punto de vista conceptual.

Por lo que se refiere al ajuste del modelo, tal y como recomiendan diferentes autores (Brown, 2006; Byrne, 2009; Hu y Bentler, 1999; Kline, 2005), para una mejor evaluación del mismo se consideraron de manera simultánea varios índices: $\chi^{2}, \chi^{2} / g l$, GFI (Goodness of Fit Index), AGFI (Adjusted Goodness of Fit Index), CFI (Comparative Fit Index), NFI (Normed Fit Index), TLI (Tucker Lewis Index) y RMSEA (Root Mean Square Error of Approximation). Siguiendo las recomendacio- nes de Steiger (1998) en el caso del RMSE $A$ se incluyeron también los intervalos de confianza para el $90 \%$. Como se puede observar en la Tabla 8, el ajuste de la escala al modelo teórico de partida es elevado, obteniéndose valores de GFI, AGFI, CFI, TLI y NFI por lo general superiores a .95. Algo similar puede decirse del valor de RMSE $A$ (por debajo del valor .06 recomendado por $\mathrm{Hu}$ y Bentler, 1999). Por otra parte, el nivel de ajuste encontrado en las dos submuestras aleatorias consideradas fue prácticamente idéntico.

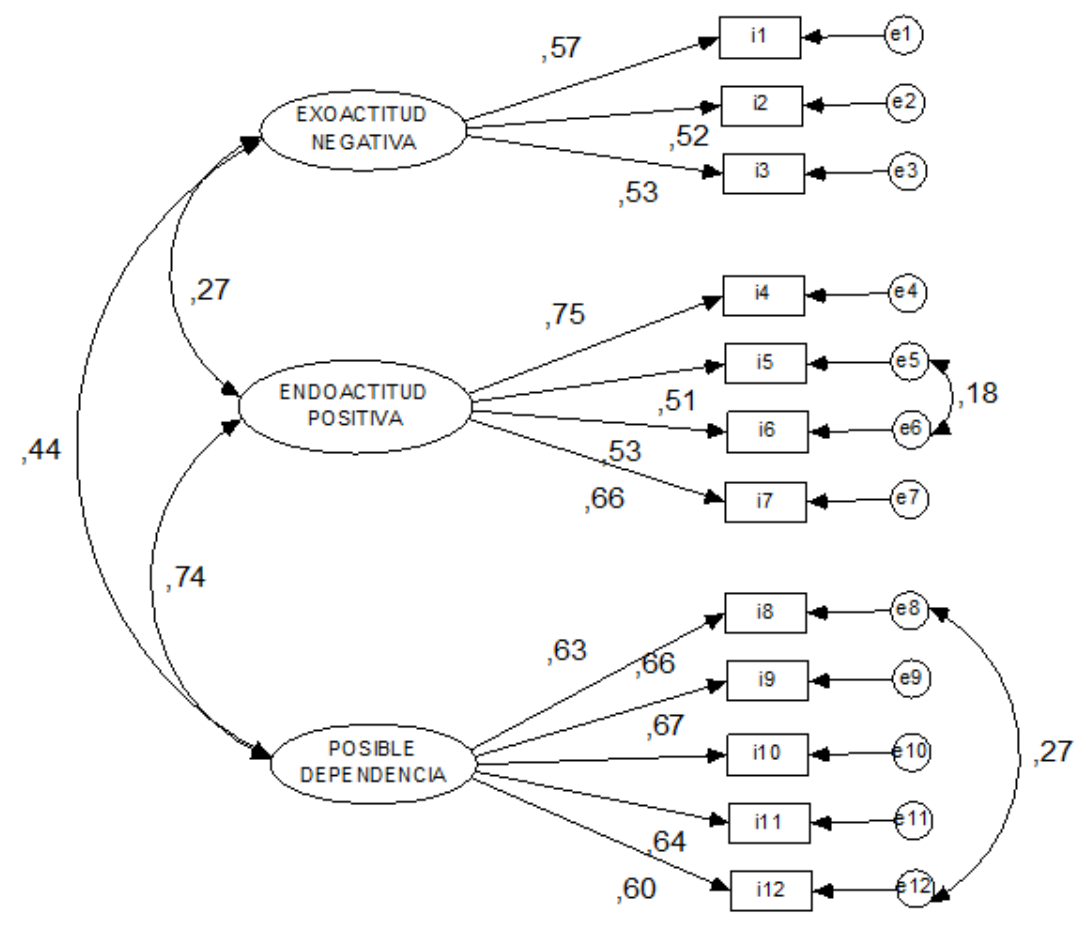

Figura 1. Parámetros estimados estandarizados del modelo $A F C$ para la escala de actitudes.

Tabla 8. Indicadores de bondad de ajuste del modelo AFC para la escala de actitudes.

\begin{tabular}{|c|c|c|c|c|c|c|c|c|c|c|}
\hline & $\chi^{2}$ & $g l$ & $p$ & $\chi^{2} / g l$ & GFI & $A G F I$ & $C F I$ & NFI & $T L I$ & $\mathrm{RMSE} A[I C]^{*}$ \\
\hline$\overline{\text { Muestra global }}$ & 311.02 & 49 & $<.001$ & 6.34 & .97 & .96 & .95 & .94 & .93 & $.053[.047-.058]$ \\
\hline Mitad 1 & 170.92 & 49 & $<.001$ & 3.49 & .97 & .95 & .96 & .94 & .94 & $.051[.043-.059]$ \\
\hline Mitad 2 & 185.73 & 49 & $<.001$ & 3.79 & .97 & .95 & .95 & .93 & .95 & $.054[.046-.062]$ \\
\hline
\end{tabular}

* Intervalo de Confianza para el estadístico RMSEA para el $90 \%$

Por último, se estudió la consistencia interna, obteniéndose un coeficiente alfa de Cronbach de .80 para la escala en su conjunto. Los valores particulares para cada dimensión fueron algo inferiores $\left(\alpha_{1}=.51 ; \alpha_{2}=.77\right.$ y $\left.\alpha_{3}=.78\right)$, especialmente en el caso de la Dimensión I, si bien conviene recordar que está compuesta por tan solo 3 elementos.

Retomando los resultados a nivel descriptivo, más allá de las propiedades psicométricas de la escala de actitudes desarrollada, cabría afirmar que los adolescentes comparten en buena medida la idea de que la "gente de su edad" hace un uso por lo general poco recomendable de la Red ("Creo que cada vez hay más gente de mi edad "enganchada" a Internet y las redes sociales"; "Algunos/as de mis amigos/as hacen un uso excesivo o poco adecuado de Internet y las redes sociales"; "Mucha gente utiliza las redes sociales para ligar, tontear, etc."). Sin embargo, cuando se trata de realizar atribuciones acerca de sí mismos, informan de un posible riesgo de dependencia muy bajo y de un nivel de apego hacia Internet y las redes sociales relativamente moderado.

A continuación se analizaron las posibles diferencias por Género, Ciclo y Titularidad del centro. 


\section{Diferencias por Género}

Aunque las principales motivaciones a la hora de utilizar la Red son similares para chicos y chicas (uso de redes sociales y descarga de archivos) es posible señalar algunas diferencias significativas $\left(\chi^{2}=441.51 ; p<.001\right)$, especialmente en el caso de la búsqueda de información relacionada con los estudios (mencionada por un $66.6 \%$ de las chicas, frente a un $54.3 \%$ de los chicos), o en la participación en juegos online (44.4\% en los varones y $15 \%$ en las mujeres).

Los chicos afirman estar más informados $\left(M_{\text {chicos }}=3.59\right.$; $\left.M_{\text {chicas }}=3.45 ; t=4.174 ; p<.001\right)$ y se muestran interesados en mayor medida por aspectos técnicos $(45.5 \%$ de los chicos frente al $27.8 \%$ de las chicas), mientras que a las chicas les preocupa más la seguridad y confidencialidad (un 49.6\% frente a un $38.8 \%$ ) y cómo buscar información de todo tipo en la Red $\left(36.3 \%\right.$ frente al 31.3\%) ( $\left.\chi^{2}=109.84 ; p<.001\right)$. Se ha encontrado también un uso mayor de Messenger en el caso de las chicas (aplicación utilizada por un $47.8 \%$ de las chicas y un $39.6 \%$ de los chicos; $\left.\chi^{2}=13.99 ; p<.001\right)$. Por lo que se refiere a las redes sociales, las mujeres mostrarían un nivel de interacción mayor que los varones (el 36.5\% de ellas ve fotos, chatea y hace comentarios, frente al $30.7 \%$ de ellos; y el $11.5 \%$ de las chicas cuelga fotos y vídeos, frente al $7.4 \%$ de los chicos). Estos, por su parte, hacen un uso significativamente mayor de los juegos (el 10.6\% de los varones frente al 6.8\% de las mujeres) $\left(\chi^{2}=117.26 ; p<.001\right)$.

Pese a que no se encuentran diferencias significativas en cuanto a la frecuencia, ni al tiempo de conexión, las chicas manifiestan un descontento significativamente mayor por no poder conectarse tanto como les gustaría (un $42.5 \%$ de las chicas frente al 30\% de los chicos; $\left.\chi^{2}=41.35 ; p<.001\right)$. Por último, es interesante señalar también el hecho de que las discusiones por causa de Internet son significativamente más frecuentes en el caso de las chicas $(24.8 \%)$ que en el de los chicos $(17.1 \%)\left(\chi^{2}=21.65 ; p<.001\right)$. Esta misma tendencia se constata en el control parental (ejercido sobre el $52.5 \%$ de las chicas frente al $39.5 \%$ de los chicos; $\chi^{2}=42.14$; $p<.001)$, lo que evidenciaría el papel diferente que los padres estarían ejerciendo en unos casos y en otros.

\section{Diferencias por Ciclo}

En primer lugar cabe señalar que la frecuencia de conexión es significativamente mayor entre los alumnos de segundo ciclo $\left(\chi^{2}=103.93 ; p<.001\right)$, con un porcentaje del $70 \%$ que se conecta diariamente, frente a un $51.3 \%$ en el caso de los adolescentes de primer ciclo. Algo similar puede decirse del tiempo de conexión, significativamente mayor entre los estudiantes de segundo ciclo (el $32.7 \%$ de los adolescentes de segundo ciclo se conecta más de dos horas diariamente, frente al $22.9 \%$ en el caso de primer ciclo; $\chi^{2}=$ $31.09 ; p<.001)$. Son además significativas las diferencias en cuanto a la franja horaria de conexión $\left(\chi^{2}=136.76\right.$; $p<$ .001). Sirva como ejemplo que en el caso de los adolescentes de segundo ciclo el porcentaje de sujetos que se conecta a Internet a partir de las $21 \mathrm{~h}$ es del $49.7 \%$, siendo casi la mi$\operatorname{tad}(28.4 \%)$ en primer ciclo.

Otro dato interesante tiene que ver con los lugares de conexión: los/as adolescentes de primer ciclo acceden a la Red comparativamente más desde casa de amigos o familiares (casi 1 de cada 4), mientras que los/as de segundo ciclo lo hacen en mayor medida desde su móvil (19.5\%), el centro escolar $(14.1 \%)$ o cualquier lugar con wifi $(19.7 \%)\left(\chi^{2}=\right.$ $52.59 ; p<.001)$. Como era de esperar, los/as adolescentes de segundo ciclo dicen estar más informados sobre Internet $\left(M_{1}{ }^{\mathrm{er}}\right.$ ciclo $\left.=3.49 ; M_{2^{\circ} \text { ciclo }}=3.56 ; t=-2.06 ; p<.05\right)$, son más autodidactas (el $73.1 \%$ frente al $58.2 \%$ ) y recurren en mayor medida a amigos como fuente de información (el 46.1\% frente al 32.4\%) $\left(\chi^{2}=115.38 ; p<.001\right)$. Por otra parte, los estudiantes de primer ciclo recurren más a familiares (el $44.8 \%$ frente al $37.5 \%$ ), lo que revela un grado de autonomía menor.

El uso de las redes sociales es el principal motivo de conexión a Internet para ambos grupos, aunque de forma más marcada en el caso de los/as mayores $(91.4 \%$ frente al $79.2 \%$ ). Son también los/as estudiantes de segundo ciclo los que señalan tanto las descargas (un $72.8 \%$ frente a un $56.1 \%$ ), el disfrute online de contenidos (el 51.6\% frente al 39.6\%), como la búsqueda de información de todo tipo $(61.9 \%$ y $59 \%$ ), entre los principales motivos de utilización de la Red. Por el contrario, son los/as de primer ciclo los que participan más en juegos online $(34.3 \%$ y $25.6 \%)\left(\chi^{2}=235.61 ; p<\right.$ $.001)$.

Como era de esperar también los/as de segundo ciclo disponen en mayor medida de correo electrónico $(94.6 \%$ y $\left.85.2 \% ; \chi^{2}=57.10 ; p<.001\right)$, Messenger $\left(93.1 \%\right.$ y $85.1 \% ; \chi^{2}$ $=37.99 ; p<.001)$ y cámara Web $\left(65.8 \%\right.$ y $60.6 \% ; \chi^{2}=6.87$; $p<.01)$. Asimismo, un $23.7 \%$ de los adolescentes de primer ciclo no cuenta con un perfil en ninguna red social, porcentaje que desciende al 5.8\% en el caso de los de segundo ciclo $\left(\chi^{2}=155.86 ; p<.001\right)$. El principal motivo de uso de las redes sociales es para ambos el contacto con amigos y familiares, sin embargo, los/as adolescentes de mayor edad aluden en mayor medida a la posibilidad de ver fotos, chatear y hacer comentarios (un $39.5 \%$ frente a un $27.3 \%$ ). Por otro lado, los/as más jóvenes aluden comparativamente más a los juegos que estas ofrecen $\left(10.2 \%\right.$ y $7.2 \%$; $\chi^{2}=159.47 ; p<$ $.001)$.

Otro dato de interés es que el porcentaje de sujetos que refiere discusiones frecuentes con sus padres a causa de Internet es casi el doble entre los estudiantes de segundo ciclo $(27.3 \%)$, que entre los de primero $(14.7 \%)\left(\chi^{2}=91.79 ; p<\right.$ $.001)$.

Por último, en lo relativo a las actitudes hacia Internet y las redes sociales, resulta muy revelador el hecho de que los adolescentes de segundo ciclo manifiesten una mayor exoactitud negativa $\left(M_{1{ }^{\text {er }} \text { ciclo }}=3.96 ; M_{2^{\circ} \text { ciclo }}=4.11 ; t=-4.07 ; p<\right.$ $.001)$, una mayor endoactitud positiva $\left(M_{1}{ }^{\text {er }}\right.$ ciclo $=3.21 ; M_{2^{\circ} \text { ciclo }}$ $=3.44 ; t=-4.68 ; p<.001) \mathrm{y}$, al mismo tiempo, un mayor riesgo de dependencia $\left(M_{1}{ }^{\text {er }}\right.$ ciclo $=2.41 ; M_{2^{\circ} \text { ciclo }}=2.69 ; t=-5.49 ; p$ $<$.001). Podría decirse, por tanto, que con la edad aumenta- 
ría la percepción o nivel de consciencia del uso peligroso que los otros pueden estar haciendo de la Red, aumenta también la simpatía, apego o vínculo con esta y, además se incrementan las conductas o manifestaciones que pueden implicar en sí mismas un mayor de riesgo de ciberdependencia.

\section{Diferencias por Titularidad del Centro}

En primer lugar, el uso regular de la Red es ligeramente menor entre los alumnos de centros públicos, siendo el porcentaje de sujetos que se conectan Nunca, Casi nunca u Ocasionalmente de un $14.6 \%$, frente al $8.6 \%$ en el caso de los que acuden a centros privados y concertados $\left(\chi^{2}=17.56 ; p<\right.$ .005). Estos últimos disponen en mayor medida de conexión a Internet en su casa $(94.3 \%$ frente al $86.7 \%)$, en su móvil $(21.8 \%$ frente al $13.4 \%)\left(\chi^{2}=75.49 ; p<.001\right)$ y en su propio cuarto $\left(64.3 \%\right.$ y $\left.59.5 \% ; \chi^{2}=4.59 ; p<.05\right)$, al igual que sucede con la cámara Web $\left(67.9 \%\right.$ y $61.1 \% ; \chi^{2}=9.97 ; p$ $<.005)$.

De igual modo, los/as estudiantes de centros privados consideran que tienen un nivel de información mayor sobre Internet $\left(M_{\text {público }}=3.49 ; M_{\text {privado }}=3.58 ; t=-2.38 ; p<.05\right)$. En cuanto a los padres, un primer dato de interés es que el porcentaje de usuarios de la Red es significativamente mayor $\left(\chi^{2}=98.72 ; p<.001\right)$ entre los progenitores de adolescentes que acuden a centros privados que públicos $(86.1 \%$ frente $67 \%$ ). Ello posiblemente esté relacionado también con el hecho de que los padres y familiares constituyan en mayor medida una fuente de información sobre Internet para sus hijos/as (el $45.1 \%$ en el caso de adolescentes que acuden a centros privados, frente al $39.4 \%$ de centros públicos; $\chi^{2}$ $=21.4 ; p<.005)$, y que ejerzan un mayor control sobre estos/as $\left(49.7 \%\right.$ en centros privados y $44.3 \%$ en públicos; $\chi^{2}=$ 7.33 ; $p<.05)$, siendo más frecuentes las discusiones en el caso de los alumnos de centros privados (un $23.8 \%$ frente a un $\left.19.7 \% ; \chi^{2}=14.77 ; p<.01\right)$.

Por último, a nivel actitudinal, en la Dimensión III (Posible Riesgo de Dependencia), se ha encontrado un promedio significativamente mayor entre los alumnos de centros privados $\left(M_{\text {público }}=2.51 ; M_{\text {privado }}=2.62 ; t=-2.19 ; p<.05\right)$.

\section{Discusión y Conclusiones}

La preocupación por el uso que los adolescentes hacen de Internet se ha visto acrecentada en los últimos años. La alarma social generada ha llevado incluso a que muchas investigaciones hayan centrado sus esfuerzos no solo en tratar de medir o calibrar la verdadera magnitud del problema, sino también en valorar si el uso de Internet puede constituir o no un tipo específico de adicción (Carbonell et al., 2012; LaRose et al., 2003; Widyanto y Griffiths, 2006), y en desarrollar instrumentos de diagnóstico adecuados (Caplan, 2002; Demetrovics et al., 2008).

En este contexto, el presente trabajo fue planteado con un doble objetivo: por un lado, disponer de datos empíricos que se traduzcan en un conocimiento más preciso y objetivo del uso que nuestros adolescentes están haciendo de Internet y las redes sociales, así como de las actitudes y percepciones que suscitan; por otro lado, el análisis de los datos habrá de facilitarnos una mejor comprensión de las relaciones que los jóvenes mantienen con la Red, identificando algunas de sus claves y promoviendo acciones preventivas que fomenten un uso más saludable o racional.

Entre los resultados más sobresalientes cabe destacar, en primer lugar, la constatación empírica de que tanto Internet como las redes sociales tienen un nivel de implantación muy elevado en la población objeto de estudio. Los datos disponibles permiten afirmar que 9 de cada 10 estudiantes de secundaria de la comunidad gallega hacen uso de Internet habitualmente (el 60\% a diario). Este resultado sería similar a los facilitados por el informe europeo EU Kids Online (Garmendia, Garitaonandia, Martínez y Casado, 2011), en el que se recoge que un 58\% de los menores españoles usan Internet todos o casi todos los días y un 34\% lo utiliza una o dos veces por semana. Otro dato coincidente con el informe europeo es que el lugar de conexión por excelencia es el propio domicilio familiar (en torno al 85\% tanto en el caso de Galicia, como de España y Europa). De igual modo, el 55\% de los adolescentes gallegos aseguran contar con conexión en su habitación, porcentaje algo superior al valor medio europeo (49\%) y al del conjunto de España (42\%). Cabe recordar, no obstante, las limitaciones muestrales del trabajo de campo, correspondiendo a nuestro país un total de 1024 entrevistas, menos de la mitad que en el presente estudio. En ese sentido, independientemente de otro tipo de limitaciones, los propios márgenes de error manejados hacen que posiblemente los datos obtenidos para Galicia pudieran representar mejor los del conjunto del estado, que los facilitados por el informe europeo EU Kids Online.

Algo similar puede decirse con relación al uso del móvil para conectarse a Internet. Así, un $15.8 \%$ de los/as adolescentes gallegos/as afirma conectarse a la Red a través del móvil, porcentaje superior al $6 \%$ que el informe europeo atribuye a España, aunque muy inferior al 31\% alcanzado para el conjunto de Europa (Garmendia et al., 2011). En cualquier caso, la diferencia respecto a Europa bien puede estar evidenciando el potencial de crecimiento de este tipo de dispositivos y alertaría de nuevos riesgos.

Por lo que se refiere a las motivaciones que subyacen al uso de la Red, la heterogeneidad de las respuestas encontradas no hace más que constatar la complejidad que, desde un punto de vista motivacional, el uso de Internet posee para los adolescentes, presentando ante ellos un rico abanico de actividades, posibilidades y "beneficios". La gama de motivos es muy amplia, siendo el más citado el hacer uso de las redes sociales $(85 \%)$, seguido de la realización de descargas (64.4\%), la búsqueda de información relacionada con los estudios $(60.2 \%)$ y el uso del correo electrónico (52.1\%), datos que vienen a coincidir con los facilitados por el informe europeo para el conjunto de España (Garmendia et al., 2011).

En cuanto a las redes sociales, el nivel de implantación es también muy elevado (el $85.1 \%$ está registrado en al menos 
una red social) y las razones de su uso vuelven a revelar la enorme riqueza motivacional subyacente (contacto online mediante chats, subir y bajar fotografías y vídeos, compartir información sobre diferentes temas y eventos, conocer y quedar con gente, cotillear, participar en juegos...).

En relación al papel ejercido por los padres, un $52.8 \%$ de los/as adolescentes señala que sus padres no lo controlan a la hora de navegar por Internet, y uno de cada cuatro afirma que sus padres no han utilizado nunca o casi nunca la Red. Se ha comprobado también que el control ejercido por los padres es significativamente menor cuando estos no hacen uso de Internet. Todos estos resultados muestran la brecha generacional existente, aunque es previsible que se reduzca con el paso de los años, y ponen de relieve la necesidad que a día de hoy existe de informar y fomentar un mayor conocimiento por parte de los padres, concienciándolos de todo lo que Internet puede reportar. Ello presumiblemente derivaría en un establecimiento más eficiente de límites y normas y en la posibilidad de convertirse en una valiosa fuente de información para sus propios hijos/as.

En cuanto a las actitudes hacia la Red, más allá de las propiedades psicométricas de la escala desarrollada (lo que la convierte en un instrumento interesante a nivel aplicado), los resultados evidencian que los/as adolescentes comparten en buena medida la idea de que la "gente de su edad" hace un uso, por lo general, poco recomendable de Internet. No obstante, cuando se trata de realizar atribuciones acerca de sí mismos, informan de un riesgo de dependencia muy bajo aunque, al mismo tiempo, de un cierto grado de apego que puede considerarse moderado.

Como ya se ha mencionado, este trabajo pretendía explorar también qué variables sociodemográficas podrían estar modulando el uso de la Red. En cuanto al Género, los resultados muestran que, comparativamente, las chicas utilizan Internet más como fuente de información relacionada con los estudios, mientras que los chicos participan más en juegos online. Estos resultados vienen a coincidir con los encontrados por Weiser (2000) y con los relativos a los menores españoles recogidos en el proyecto europeo EU Kids Online (Garmendia et al., 2011). De igual modo, los chicos dicen poseer mayor nivel de información (Li y Kirkup, 2007). Por otra parte, los resultados refuerzan la idea de que no existen diferencias significativas en cuanto a la frecuencia y tiempo de conexión, tal y como plantearon trabajos anteriores como el de Gross (2004). Sí se han encontrado diferencias significativas en cuanto al descontento por no poderse conectar todo lo que les gustaría, mayor en el caso de las chicas. Este hecho, unido a la mayor frecuencia de discusiones con los padres y al mayor control ejercido por parte de estos, sugiere dos posibles explicaciones: por un lado, una mayor precocidad por parte de las mujeres y, por otro, una actitud más protectora por parte de los padres.

En cuanto a las diferencias encontradas por Ciclo, estas no hacen más que constatar el papel de la Edad. En concreto, el tiempo de uso de Internet así como la frecuencia de conexión es significativamente mayor entre los adolescentes de segundo ciclo. Este resultado coincide con los datos del proyecto EU Kids Online, tanto para la muestra española como para el conjunto de Europa (Garmendia et al., 2011). Son diversos los datos que reflejan una mayor autonomía por parte de los adolescentes de segundo ciclo a la hora de utilizar Internet (se conectan más desde su móvil, desde el centro escolar o cualquier lugar con wifi; dicen estar más informados, son más autodidactas y recurren en mayor medida a amigos como fuente de información; amplían el abanico de posibilidades que les brinda Internet, haciendo un uso mayor de las redes sociales, búsqueda de información, descargas o disfrute online de contenidos; disponen en mayor medida de correo electrónico, Messenger y cámara Web, etc.). En lo relativo a las actitudes, los/as adolescentes de segundo ciclo presentan mayores puntuaciones en todas las dimensiones, lo cual refleja una mayor conciencia de los riesgos que Internet entraña (Exoactitud Negativa) pero, al mismo tiempo, un mayor grado de adhesión y simpatía (Endoactitud Positiva), así como un mayor Riesgo de Dependencia (posiblemente ligado al mayor uso que realizan de la Red).

De igual modo, el porcentaje de adolescentes que discute con sus padres a causa de Internet es el doble que en los de primer ciclo. Ello hace pensar que la influencia positiva que pueden llegar a ejercer los padres en el uso saludable de la Red será mayor cuanto a más temprana edad se fomente y, por tanto, invita a una mayor información y sensibilización.

Por lo que se refiere a la Titularidad del Centro, se ha encontrado que la frecuencia de conexión es mayor entre los/as adolescentes que asisten a centros privados y concertados, resultado congruente con el obtenido por Garmendia et al., (2011). De igual modo, estos poseen en mayor medida conexión en casa (e incluso en su propio cuarto), al igual que dispositivos como cámara Web o conexión a través del teléfono móvil. En la misma línea, los/as estudiantes de centros privados/concertados se muestran más informados y son los que acuden en mayor medida a sus familiares como fuente de información. Estas diferencias vuelven a coincidir con las encontradas por Garmendia et al. (2011), aunque en su caso las diferencias se establecen entre niveles socioeconómicos.

Tratando de integrar los resultados obtenidos, cabría decir en primer lugar que no parece justificada una actitud alarmista ante el problema. Las cifras encontradas revelan un uso "esperable" de Internet y las redes sociales entre los adolescentes, siendo en buena medida coherentes con los datos presentados en estudios precedentes (Bringué y Sádaba, 2009; Garmendia et al., 2011). No obstante, los elevados niveles de implantación detectados, así como la multiplicidad de usos y motivaciones subyacentes, aconsejan una postura cautelosa al respecto, más aún si se tiene en cuenta el papel residual que parecen ejercer los padres y la enorme brecha generacional existente.

Si a partir de estos datos se intenta estimar el volumen de adolescentes que podrían estar haciendo un uso aparentemente peligroso de la Red (se conectan diariamente, durante más de dos horas, no se conectan todo lo que les gustaría y 
tienen frecuentes discusiones con sus padres a causa de Internet), podríamos estar hablando de algo más de un $2 \%$ de individuos; dato que extrapolado a la población gallega de estudiantes de ESO representaría aproximadamente unos 2000 casos. Si se analiza su distribución en diferentes variables, puede comprobarse además que este porcentaje es significativamente mayor entre las mujeres $\left(\chi^{2}=4.01 ; p<.05\right.$; $2.9 \%$ frente a un $1.5 \%$ en hombres); entre escolares de segundo ciclo $\left(\chi^{2}=6.23 ; p<.05 ; 3 \%\right.$ frente a un $1.3 \%$ en primer ciclo), y ligeramente mayor en los centros privados o concertados $(2.7 \%$ frente a un $2 \%$ en centros públicos). Se comprobó además que este grupo de individuos presentan puntuaciones significativamente mayores en la Dimensión de Posible Riesgo de Dependencia de la escala de actitudes desarrollada $(t=-12.935 ; p<.001)$, lo que proporciona evidencias de su validez de criterio y/o capacidad discriminativa.

En definitiva, la realidad que describen los resultados presentados coincide con la visión proporcionada por buena parte de los trabajos previos, aunque en muchas ocasiones estos se hayan centrado en aspectos excesivamente concretos (lo que impide disponer de una visión global del problema objeto de estudio), y en otros casos hayan sido obtenidos a partir de muestras muy limitadas, como es el caso de los datos proporcionados por el propio Informe europeo EU Kids Online, para el conjunto del estado español. Pero más allá de disponer de una visión algo más completa y objetiva de la realidad, la intención del presente trabajo era contribuir al diseño de estrategias y líneas de actuación a nivel de prevención y control, que favorezcan un uso más saludable de Internet entre los más jóvenes.

En ese sentido, habida cuenta de que Internet es utilizado principalmente en el entorno del propio hogar, corresponde a los padres ejercer un control efectivo de su uso, por lo que se hace necesario que dispongan de un buen conocimiento de todo lo que tiene que ver con la Red y las nuevas tecnologías, convirtiéndose así una fuente de información y un verdadero elemento de referencia para sus hijos. Tal y como recomienda Mayorgas (2009), es necesario reforzar medidas que insten a los padres a que ejerzan un control más estrecho y responsable del uso de Internet que hacen sus hijos/as, tanto en su propia casa (ubicando los ordena-

\section{Referencias}

Armstrong, L., Phillips, J., y Saling, L. (2000). Potential determinants of heavier Internet usage. International Journal of Human-Computer Studies, 53, $537-550$.

Aslanidou, S. y Menexes, G. (2008). Youth and the Internet: Uses and practices in the home. Computers \& Education, 51, 1375-1391. doi:10.1016/j.compedu.2007.12.003

Asociación para la Investigación de Medios de Comunicación [AIMC]. (2014). Navegantes en la red. $16^{a}$ encuesta AIMC a usuarios de Internet. Madrid: Autor. Recuperado de http://download.aimc.es/aimc/J5d8yq/ macro2013.pdf

Beranuy, M., Chamarro, A., Graner, C., y Carbonell, X. (2009). Validación de dos escalas breves para evaluar la adicción a Internet y el abuso de móvil. Psicothema, 21, 480-485. dores en lugares comunes), como a través de otras vías o dispositivos (teléfono móvil, conexiones wifi, ciber, etc.), así como en lo relativo al control de los contenidos. Asimismo, sería recomendable que los padres limitasen tanto la frecuencia de conexión, como el tiempo que sus hijos/as pasan en la Red.

En segundo lugar, los resultados obtenidos advierten de la necesidad de trabajar con los centros educativos. Estos deben convertirse en una fuente relevante de información y formación con relación a Internet y en un interlocutor válido para modular los conocimientos, actitudes y hábitos de uso entre los/as adolescentes. Más allá de las tradicionales "clases de informática", sería recomendable establecer en los propios diseños curriculares una formación integral sobre Internet, bajo una orientación psicosocial, que favorezca un uso saludable.

La tercera línea o frente de actuación debe desarrollarse a nivel institucional. Las diferentes administraciones deben asumir su responsabilidad a través de medidas concretas como: (1) favorecer la realización periódica de estudios que permitan hacer un seguimiento objetivo y puntual del problema; (2) promover la elaboración y validación de herramientas de screening que hagan posible un cribado del uso peligroso y la dependencia de Internet entre los más jóvenes, posibilitando una rápida detección y consecuente derivación a los servicios de salud o dispositivos asistenciales que proceda; (3) realizar campañas de información y sensibilización dirigidas a segmentos o targets concretos (padres, educadores...); (4) implicar y coordinar a diferentes instituciones, órganos o agentes sociales (Consejerías de Educación, Defensor del Pueblo, Institutos de Consumo, asociaciones de padres, asociaciones de consumidores, etc.); y (5) promover que las propias firmas comerciales y proveedores de Internet implementen mecanismos de control que puedan ser utilizados por padres y educadores de modo sencillo y efectivo a la hora de controlar y limitar el uso de Internet por parte de los/as adolescentes.

Agradecimientos.- Este trabajo fue realizado gracias a un convenio realizado con el Valedor do Pobo de Galicia y financiado por la Consellería de Educación y Ordenación Universitaria de la Xunta de Galicia.

Brenner, V. (1997). Psychology of computer use: Parameters of Internet use, abuse and addiction: the first 90 days of the internet usage survey. Psychological Reports, 80, 879-882.

Bringué, X. y Sádaba, C. (2009). La generación interactiva en España: Niños y adolescentes ante las pantallas (1a. ed.). Barcelona y Madrid: Ariel y Fundación Telefónica.

Brown, T. A. (2006). Confirmatory factor analysis for applied research. New York: Guilford Press.

Byrne, B. M. (2009). Structural equation modeling with AMOS: Basic concepts, applications, and programming (2nd ed.). London: Psychology Press.

Caplan, S. E. (2002). Problematic Internet use and psychosocial well-being: Development of a theory-based cognitive-behavioral measurement instrument. Computers in Human Behavior, 18, 553-575. 
Carbonell, X., Chamarro, A., Griffiths, M., Oberst, U., Cladellas, R. y Talarn, A. (2012). Problematic Internet and cell phone use in Spanish teenagers and young students. Anales de Psicología, 28, 789-796.

Carbonell, X., Fúster, H., Chamarro, A. y Oberst, U. (2012). Adicción a Internet y móvil: Una revisión de estudios empíricos españoles. Papeles del Psicólogo, 33, 82-89.

Castellana, M., Sánchez-Carbonell, X., Graner, C. y Beranuy, M. (2007). El adolescente ante las tecnologías de la información y la comunicación: Internet, móvil y videojuegos. Papeles del Psicólogo, 28, 196-204.

Chen, K., Tarn, J. M. y Han, B.T. (2004). Internet dependency: Its impact on online behavioral patterns in E-commerce. Journal Human Systems Management, 23, 49-58.

Chou, C., y Hsiao, M. C. (2000). Internet addiction, usage, gratification, and pleasure experience: The Taiwan college student's case. Computers \& Education, 35, 65-80.

Chow, S. L., Leung, G. M., Ng, C. y Yu, E. (2009). A Screen for Identifying Maladaptive Internet Use. International Journal of Mental Health \& Addiction, 7, 324-332. doi:10.1007/s11469-008-9170-4

Curran, P. J., West, S. G., y Finch, J. F. (1996). The robustness of test statistics to nonnormality and specification error in confirmatory factor analysis. Psychological Methods, 1, 16-29.

Davis R. A. (2001). A cognitive-behavioral model of pathological Internet use. Computers in Human Behavior 2001, 17, 87-95.

Davis, R. A., Flett, G. L. y Besser, A. (2002). Validation of a new scale for measuring problematic Internet use: implications for pre-employment screening. CyberPsychology \& Behavior, 5, 331-345.

DeBell, M. y Chapman, C. (2003). Computer and Internet use by children and adolescents in 2001. Education Statistics Quarterly, 5(4), 7-11.

Demetrovics, Z. Szeredi, B. y Rózsa, S. (2008). The three-factor model of Internet addiction: The development of the Problematic Internet Use Questionnaire. Behavior Research Methods, 40, 563-574. doi: 10.3758/BRM.40.2.563

Douglas, A. C., Mills, J. E., Niang, M., Stepchenkova, S., Byun, S., Ruffini, ... y Blanton, M. (2008). Internet addiction: Meta-synthesis of qualitative research for the decade 1996-2006. Computers in Human Behavior, 24, 3027-3044. doi:10.1016/j.chb.2008.05.009

Echeburúa, E. (2003) ¿Adicciones sin drogas? Las nuevas adicciones. Bilbao: Desclée de Brouwer.

Echeburúa, E. y De Corral, P. (2010). Adicción a las nuevas tecnologías y a las redes sociales en jóvenes: un nuevo reto. Adicciones, 22, 91-96.

García-Piña, C. A. (2008). Riesgos del uso de internet por niños y adolescentes. Estrategias de seguridad. Acta Pediátrica de México, 29, 273-279.

Garmendia, M., Garitaonandia, C., Martínez, G. y Casado, M. A. (2011). Riesgos y seguridad en internet: Los menores españoles en el contexto europeo. Universidad del País Vasco, Bilbao: EU Kids Online. Recuperado de http://www.sociologia.ehu.es/s0018eukidsct/es/contenidos/noticia/e ukids_informe_280311/es_not/adjuntos/Informe_Espa\%C3\%B1a_co mpleto_red.pdf

Goldberg, I. (1995). Internet addictive disorder (LAD) diagnostic criteria. Recuperado de http:// www.psycom.net/iadcriteria.html.

Gracia, M., Vigo, M., Fernández, J. y Marcó, M. (2002). Problemas conductuales relacionados con el uso de Internet: Un estudio exploratorio. Anales de Psicologia, 18, 273-292.

Graner, C., Beranuy, M., Sánchez, X., Chamarro, A. y Castellana, M. (2007). ¿Qué uso hacen los jóvenes y adolescentes de Internet y del móvil? En L. Álvarez, J. Evans y O. Crespo (Ed. lit.), Foro Internacional Sobre Comunicación E Xuventude. Comunciación e Xuventude: Actas do Foro Internacional (pp.71-90). Santiago de Compostela: Colexio Profesional de Xornalistas de Galicia.

Green, L., Brady, D., Ólafsson, K., Hartley, J. y Lumby, C. (2011). Risks and safety for Australian children on the internet. Full findings. Kelvin Grove QLD: ARC Centre of Excellence for Creative Industries and Innovation. Recuperado https://www.ecu.edu.au/_data/assets/pdf_file/0009/294813/UKids-Online-Survey.pdf

Greenfield, D. N. (1999). Psychological characteristics of compulsive Internet use: a preliminary analysis. CyberPsychology \& Behaviour, 2, 403-412.

Griffiths, M. (2000). Does internet and computer "addiction" exist? Some case study evidence. CyberPsychology \& Behavior, 3, 211-218.
Gross, E.F. (2004). Adolescent Internet use: What we expect, what teens report. Journal of Applied Developmental Psychology, 25, 633-649. doi:10.1016/j.appdev.2004.09.005

Hansen, S. (2002). Excessive Internet usage or "Internet addiction"? The implications of diagnostic categories for student users. Journal of Comput er Assisted Learning, 18, 232-236. doi: 10.1046/j.1365-2729.2002.t01-200230.x

Hu, L. y Bentler, P. M. (1999). Cutoff criteria for fit indexes in covariance structure analysis: conventional criteria versus new alternatives. Structural Equation Modeling: A Multidisciplinary Journal, 6, 1-55.

Instituto Nacional de Estadística [INE]. (2013). Encuesta sobre equipamiento y uso de tecnologías de información y comunicación en los hogares (TIC-H). Madrid: Autor. Recuperado de http://www.ine.es/prensa/np803.pdf

Instituto Nacional de Tecnologías de la Comunicación. (2009). Estudio sobre bábitos seguros en el uso de las TIC por niños y adolescentes y e-confianza de su. padres. León: Autor. Recuperado de http://aui.es/IMG/pdf_estudio_habitos_seguros_menores_y_econfia nza_padres_versionfinal accesible inteco.pdf

Jenaro, C., Flores, N., Gómez-Vela, M., González-Gil, F., y Caballo, C. (2007). Problematic Internet and cell-phone use: Psychological, behavioral and health correlates. Addiction Research \& Theory, 15, 309-320. doi:10.1080/16066350701350247

Kandell, J. J. (1998). Internet addiction on campus: The vulnerability of college students. CyberPsychology \& Behavior, 1, 11-17.

Kline, R. B. (2005). Principles and Practice of Structural Equation Modeling (2nd ed.). New York: The Guilford Press.

LaRose, R., Lin, C. A. y Eastin, M. S. (2003). Unregulated Internet Usage: Addiction, Habit, or Deficient Self-Regulation? Media Psychology, 5, 225 253. doi:10.1207/S1532785XMEP0503 01

Lenhart, A., Madden, M., Smith, A., Purcell, K., Zickuhr, K. y Rainie, L. (2011). Teens, kindness and cruelty on social network sites: How American teens navigate the new world of "digital citizenship". Washington, D.C.: Pew Research Center's Internet \& American Life Project. Recuperado de http://pewinternet.org/ /media/Files/Reports/2011/PIP_Teens_Ki ndness_Cruelty_SNS_Report_Nov_2011_FINAL_110711.pdf

Li, N. y Kirkup, G. (2007). Gender and cultural differences in Internet use: A study of China and the UK. Computers \& Education, 48, 301-317. doi:10.1016/j.compedu.2005.01.007

Livingstone, S. y Haddon, L. (2009). EU Kids Online: Final report. London: LSE, EU Kids Online. Recuperado de http://eprints.lse.ac.uk/24372/1/D6.5_EU-Kids-Online-FinalReport.pdf

Livingstone, S. y Haddon, L. (2011). EU Kids Online III. A new project. London: LSE, EU Kids Online. Recuperado de http://www2.lse.ac.uk/media@1se/research/EUKidsOnline/Home.as px

Livingstone, S., Haddon, L., Görzig, A. y Ólafsson, K. (2011a). EU Kids Online: Final Report. London: LSE, EU Kids Online. Recuperado de http://www.internetsafety.ie/Website/OIS/OISWeb.nsf/page/DPCY -8LXK2K15311322-en/\$File/Final\%20report.pdf

Livingstone, S., Haddon, L., Görzig, A. y Ólafsson, K. (2011b). Risks and safety on the internet: The perspective of European children. Full findings. London: LSE, EU Kids Online. Recuperado de http://eprints.lse.ac.uk/33731/1/Risks_and_safety_on the internet t he_perspective_of_European_children.pdf

Luengo, A. (2004). Adicción a Internet: conceptualización y propuesta de intervención. Revista Profesional Española de Terapia Cognitivo-Conductual, 2 22- 52

Mayorgas, M. J. (2009). Programas de prevención de la adicción a las nuevas tecnologías en jóvenes y adolescentes. En E. Echeburúa, F.J. Labrador y E. Becoña (eds.), Adicción a las nuevas tecnologias en adolescentes y jóvenes (pp. 221-249). Madrid: Pirámide.

Meerkerk G. M., Van den Eijnden, R. J. J. M. y Garretsen, H. F. L. (2006). Predicting compulsive Internet use: It's all about sex! CyberPsychology \& Behavior, 9, 95-103. doi:10.1089/cpb.2006.9.95.

Morahan-Martin, J. y Schumacher, P. (2000). Incidence and correlates of pathological Internet use among college students. Computers in Human Behavior, 16, 13-29. 
Patchin, J. W. y Hinduja, S. (2010). Changes in adolescent online social networking behaviors from 2006 to 2009. Computers in Human Behavior, 26, 1818-1821. doi:10.1016/j.chb.2010.07.009

Rodríguez, M. N. y Ruíz, M. A. (2008). Atenuación de la asimetría y de la curtosis de las puntuaciones observadas mediante transformaciones de variables: incidencia sobre la estructura factorial. Psicológica, 29, 205-227.

Ruiz- Olivares, R., Lucena, V., Pino, M. J. y Herruzo, J. (2010). Análisis de comportamientos relacionados con el uso/abuso de Internet, teléfono móvil, compras y juego en estudiantes universitarios. Adicciones, 22, 301310.

Scherer, K. (1997). College life online: healthy and unhealthy Internet use. Journal of College Life and Development, 38, 655-666.

Schumacher, P. y Morahan-Martin, J. (2001). Gender, Internet and computer attitudes and experiences. Computers in Human Behavior, 17, 95-110.

Seybert, H. y Reinecke, P.(2013). ICT (information and communication technology) usage in households and by individuals. Ciudad de Luxemburgo: Eurostat European Comission. Recuperado de http://epp.eurostat.ec.europa.eu/statistics_explained/index.php/Intern et_use_statistics_-_individuals

Shapira, N. A., Lessig, M. C., Goldsmith, T. D., Szabo, S. T., Lazoritz, M., Gold, M. S. y Stein, D. J. (2003). Problematic internet use: Proposed classification and diagnostic criteria. Depression and Anxiety, 17, 207-216. doi 10.1002/da.10094

Steiger, J. H. (1998). A note on multiple sample extensions of the RMSEA fit index. Structural Equation Modeling: A Multidisciplinary Journal, 5, 411419.

Subrahmanyam, K. y Lin, G. (2007). Adolescents on the net: Internet use and well-being. Adolescence, 42, 659-677.

Thatcher, A. y Goolam, S. (2005). Development and psychometric properties of the Problematic Internet Use Questionnaire. South African Journal of Psychology, 35, 793-809.

Tomás, J. M. y Oliver, A. (1998) Efectos de formato de respuesta y método de estimación en el análisis factorial confirmatorio. Psicothema, 10, 197 208.
Viñas, F. (2009). Uso autoinformado de Internet en adolescentes: perfil psicológico de un uso elevado de la red. International Journal of Psychology and Psychological Therapy, 9, 109-122.

Weiser, E. B. (2000). Gender Differences in Internet Use Patterns and Internet Application Preferences: A Two-Sample Comparison. CyberPsychology \& Behavior, 3, 167-178.

Weiser, E. B. (2001). The functions of Internet use and their social and psychological consequences. CyberPsychology \& Behavior, 4, 723-743.

Widyanto, L. y Griffiths, M. (2006). 'Internet addiction': A critical review. International Journal of Mental Health \& Addiction, 4, 31-51. doi: 10.1007/s11469-006-9009-9

Yang, C. K., Choe, B. M., Baity, M., Lee, J. H. y Cho, J. S. (2005). SCL-90-R and $16 \mathrm{PF}$ profiles of senior high school students with excessive Internet use. Canadian Journal of Psychiatry, 50, 407-414.

Yang, S.C. y Tung, C.J. (2007). Comparison of Internet addicts and nonaddicts in Taiwanese high school. Computers in Human Behavior, 23, 7996. doi:10.1016/j.chb.2004.03.037

Yellowlees, P. M. y Marks, S. (2007). Problematic Internet use or Internet addiction? Computers in Human Behavior, 23, 1447-1453. doi:10.1016/j.chb.2005.05.004

Young, K. S. (1996). Psychology of computer use: XL. Addictive use of the Internet: A case that breaks the stereotype. Psychological Reports, 79, 899902.

Young, K. S. (1998a). Internet addiction: The emergence of a new clinical disorder. CyberPsychology \& Behavior, 1, 237-244.

Young, K. S. (1998b). Caught in the Net. How to recognize Internet addiction and a winning strategy for recovery. New York, NY: John Wiley \& Sons, Inc.

Young, K. S. (1999). Internet addiction: Symptoms, evaluation, and treatment. En L. VandeCreek y T. L. Jackson (Eds.), Innovations in clinical practice: A source book (pp. 19-31). Sarasota, FL: Professional Resource.

(Artículo recibido: 26-9-2012; revisado: 7-2-2013; aceptado: 14-1-2013) 